\title{
Development of a method to characterize high-protein dairy powders using an ultrasonic flaw detector
}

\author{
M. Hauser and J. K. Amamcharla ${ }^{1}$ \\ Department of Animal Sciences and Industry, Food Science Institute, Kansas State University, Manhattan 66506
}

\begin{abstract}
Dissolution behavior of high-protein dairy powders plays a critical role for achieving functional and nutritional characteristics of a finished food product. Current methods for evaluating powder dissolution properties are time consuming, difficult to reproduce, and subjective. Ultrasound spectroscopy is a rapid and precise method, but requires expensive equipment and skilled technicians to carry out the tests. In the present study, an ultrasonic flaw detector (UFD) was used as an economical alternative to characterize the powder dissolution properties. The objective of study was to develop a method to characterize the dissolution behavior of milk protein concentrate (MPC) using a UFD. The experimental setup included a UFD connected to a $1-\mathrm{MHz}$ immersion transducer that was kept a constant distance from a reflector plate. To validate the method, 2 batches of MPC80 from a commercial manufacturer were procured and stored at 25 and $40^{\circ} \mathrm{C}$ for 4 wk. Focus beam reflectance measurement and solubility index were used as reference methods. Relative ultrasound velocity and ultrasound attenuation were acquired during the dissolution of MPC samples. To characterize the MPC dissolution, 4 parameters including standard deviation of relative velocity, area under the attenuation curve, and peak attenuation were extracted from ultrasound data. As the storage temperature and time increased, the area under the attenuation curve and peak height decreased, indicating a loss of solubility. The proposed UFD-based method was able to capture the changes in dissolution of MPC during storage at 25 and $40^{\circ} \mathrm{C}$. It was observed that a high-quality MPC had a low standard deviation and a larger area under the attenuation curve. As the MPC aged at $40^{\circ} \mathrm{C}$, the particle dispersion rate decreased and, consequently, an increase in standard deviation and reduction in area were observed. Overall, the UFD can be a low-cost method to characterize the dissolution behavior of high-protein dairy powders.
\end{abstract}

Received June 14, 2015.

Accepted October 12, 2015.

${ }^{1}$ Corresponding author: Jayendra@ksu.edu
Key words: ultrasonic flaw detector, milk protein concentrate, solubility

\section{INTRODUCTION}

When choosing a high-protein dairy powder, such as milk protein concentrate (MPC) or milk protein isolate, dissolution behavior is an important property to consider. High-protein content in MPC yields a powder that is typically less soluble than skim milk powder (Chandan and Kilara, 2011). Nutritional drinks, fermented dairy drinks, and various other food products use MPC to improve nutritional and functional properties. A slowly dissolving powder can complicate production by clogging filters and forming a sedimentation layer (Corredig, 2009; Chandan and Kilara, 2011). Consequently, the finished product may not have the intended nutritional and functional characteristics, such as protein content and water-holding capacity, respectively.

The solubility of MPC is affected by intrinsic and extrinsic parameters, such as protein content, dissolution temperature, and storage conditions. Below ambient temperatures and at a low relative humidity, MPC can be stored for up to 6 to 8 mo without adversely affecting the solubility. However, storage temperatures above $40^{\circ} \mathrm{C}$ drastically reduce the solubility of high-protein MPC powders (Agarwal et al., 2015). Current methods for evaluating dissolution characteristics of powders include the Baumann method (Wallingford and Labuza, 1983), filtration or centrifugation tests (Kneifel et al., 1991), and paste-water retention (Quinn and Paton, 1979). Anema et al. (2006) used solubility index as a method to study the effect of storage temperature on the solubility of MPC. These methods are time consuming, lack precision, and are difficult to reproduce. A possible alternative is to use ultrasound spectroscopy as a tool to monitor powder dissolution properties (Fang et al., 2008).

Ultrasound is defined as sound waves that have a frequency above the human hearing of $20 \mathrm{kHz}$. Lowintensity ultrasound has a power below $1 \mathrm{~W} / \mathrm{cm}^{2}$ and a frequency above $100 \mathrm{kHz}$ (Pico, 2012). Low-intensity ultrasound-based techniques have the advantage of 
being rapid, precise, and nondestructive (Dolatowski et al., 2007). In dairy foods applications, low-intensity ultrasound has successfully been used to monitor rennet coagulation (Gunasekaran and Ay, 1996; Corredig et al., 2004) and to identify internal defects and foreign objects in cheese (Leemans and Destain, 2009; Nassar et al., 2010). Through-transmission and pulse-echo modes are used in ultrasound-based techniques for evaluating quality of food products. However, McClements (1995) supported the pulse-echo mode, as it is easy to design and operate and is automated. Moreover, Povey and McClements (1988) stated that a pulse-echo method has the lowest cost for ultrasonic testing. Richard et al. (2012) demonstrated that ultrasound spectroscopy in a through-transmission mode can monitor the interactions between the dairy-based powders and solvents, and can be correlated with the powder's solubility. Meyer et al. (2006) also used an ultrasound spectrometer in pulse-echo mode to correlate the attenuation coefficient, an ultrasound spectroscopy parameter, with the visual reconstitution test for instant milk powder.

The literature provides evidence that the ultrasound spectroscopy can be a valuable tool in characterizing powder dissolution properties. Expensive instrumentation and the need for skilled technicians to perform tests keep ultrasound spectroscopy from being widely used in the dairy industry for routine testing of dairy powders. A commercially available and portable ultrasonic flaw detector (UFD) provides an economical alternative to ultrasound spectroscopy. A UFD costs around $\$ 5,000$, which is a fraction of the cost of an ultrasound spectrometer; UFD are commonly used in the construction industry to detect flaws and cracks in welds, metal, and structures (Olympus, 2007).

The objective of our study was to develop and validate a new UFD-based rapid method to characterize the dissolution behavior of high-protein dairy powders. The current study focused on developing and evaluating the proposed method using milk protein concentrate with $80 \%$ protein (MPC80) as a model system.

\section{MATERIALS AND METHODS}

\section{Experimental Design}

Milk protein concentrate 80 was used as a model system for the development and evaluation of the proposed method. Initially, UFD parameters, such as powder concentration, stirring method, ultrasound path length (distance between the reflector plate and transducer), damp, and energy, were optimized to increase the signal-to-noise ratio and also to collect as much ultrasound data as possible. To evaluate the method, 2 batches of commercially available MPC 80 were pro- cured and stored for up to 4 wk at 25 and $40^{\circ} \mathrm{C}$ to produce powders with different dissolution characteristics. The dissolution characteristics of powders were measured using the proposed UFD-based method as well as using a focused beam reflectance measurement (FBRM) technique and solubility index as reference methods.

\section{Experimental Setup}

Figure 1A shows the experimental setup consisting of a UFD (Epoch LTC, Olympus Scientific Solutions, Waltham, MA), FBRM (Particle Track E25, Mettler Toledo, Columbus, OH), an immersion transducer (V303-SU; Olympus Scientific Solutions,), a purposebuilt transducer holder, and a 4-bladed overhead stirrer (Caframo, Georgian Bluffs, Ontario, Canada) that was placed $10 \mathrm{~mm}$ from the bottom of the beaker. A temperature-controlled water bath (Fisher Scientific, Pittsburgh, PA) maintained the powder dissolution temperature at $40 \pm 0.1^{\circ} \mathrm{C}$.

UFD. A UFD in pulse-echo mode was connected to a $1-\mathrm{MHz}$ immersion transducer as shown in Figure 1A. A stainless steel holder (Figure 1B) was fabricated at a local machine shop to hold the ultrasonic transducer and also to keep the ultrasound path length constant throughout an experiment. The holder consisted of a top and a bottom plate with a diameter of $48.34 \mathrm{~mm}$ and thickness of $1.3 \mathrm{~mm}$. The top and bottom plates were placed in such a way that the ultrasound signal traveled through the medium, reflected off the bottom plate, and returned to the transducer. Before adding powder, the stirrer was set at $400 \mathrm{rpm}$ and ultrasound data were collected for water at $40^{\circ} \mathrm{C}$ as a baseline.

$\boldsymbol{F B R} \boldsymbol{M}$. An FBRM was used as a reference method to monitor the dissolution of powder. The FBRM was set at a $30^{\circ}$ angle to the vertical axis and $20 \mathrm{~mm}$ from the bottom of the beaker. Data from the FBRM was acquired with the icFBRM 4.3 (Mettler Toledo) program and counted the number of particles in the following categories: $<10 \mu \mathrm{m}, 10-50 \mu \mathrm{m}, 50-150 \mu \mathrm{m}, 300-1,000$ $\mu \mathrm{m}$. The change in particle counts was used to monitor the dissolution characteristics of MPC. In this study, only particles between 10 and $150 \mu \mathrm{m}$ were considered.

\section{Optimization of UFD-Based Method Parameters}

Preliminary studies were carried out using MPC80 as a model system to determine the optimum settings, including powder concentration $(2.5,5,7.5$, and $10 \%$, wt/wt), stirring speed (400-900 rpm), path length (17.5-50 mm), damp (50-400 ohms), and energy (100-400 V). 


\section{Deriving Parameters from UFD}

Figure 2 shows a typical ultrasound signal with the amplitude for the first and second echo. The timeof-flight and amplitude data were exported from GageView Pro (Olympus Scientific Solutions) to Microsoft Excel (Microsoft, Redmond, WA) and used to calculate the ultrasound velocity and attenuation. Ultrasound velocity (V) was calculated using Equation 1, where d is the distance between the transducer and the bottom reflector plate, and $t$ is time-of-flight, the time taken for the ultrasound wave to travel a distance of $2 \mathrm{~d}$ :

$$
\mathrm{V}\left(\frac{\mathrm{m}}{\mathrm{s}}\right)=\frac{2 \mathrm{~d}}{\mathrm{t}}
$$

From the ultrasound velocity, relative ultrasound velocity was calculated as a ratio of ultrasound velocity of the solution containing powder to that of distilled water at $40^{\circ} \mathrm{C}$. The ultrasound attenuation $(\alpha)$ was calculated using Equation 2, where $\mathrm{A}_{0}$ and $\mathrm{A}$ represent the ultrasound amplitude for the first and second echo, respectively:

$$
\alpha(\text { Neper } / \mathrm{mm})=\frac{\ln \left(\frac{\mathrm{A}_{\mathrm{o}}}{\mathrm{A}}\right)}{2 \mathrm{~d}} .
$$

Relative ultrasound velocity and attenuation were plotted against powder dissolution time. From these curves, the standard deviation of relative ultrasound velocity from $900-1,800 \mathrm{~s}$, attenuation peak height (maximum attenuation), attenuation peak time (time to reach maximum attenuation), and area under the attenuation curve were extracted to characterize powder dissolution. The area under the attenuation curve was calculated using the trapezoidal rule. The derived ultrasound

\section{(a)}

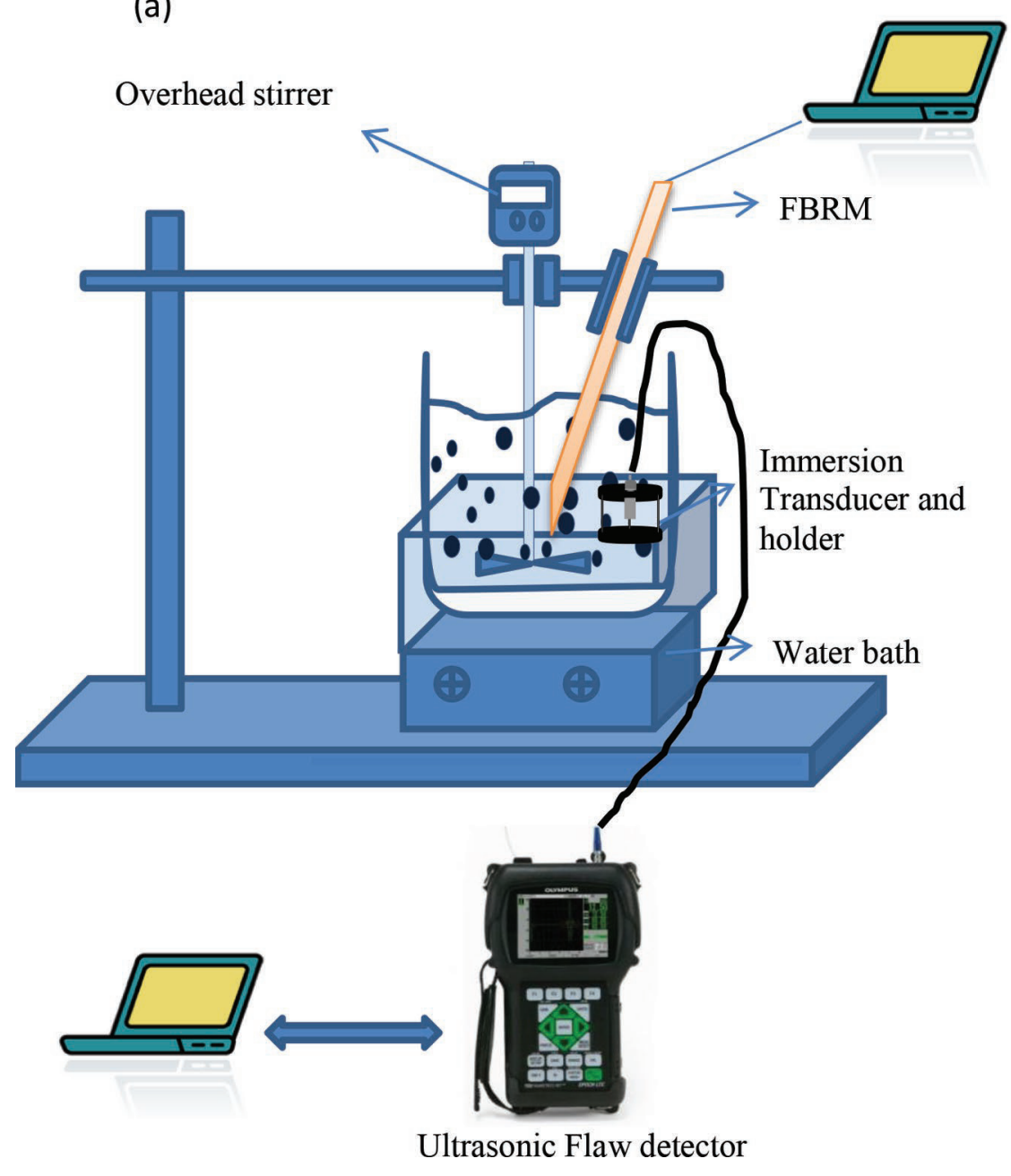

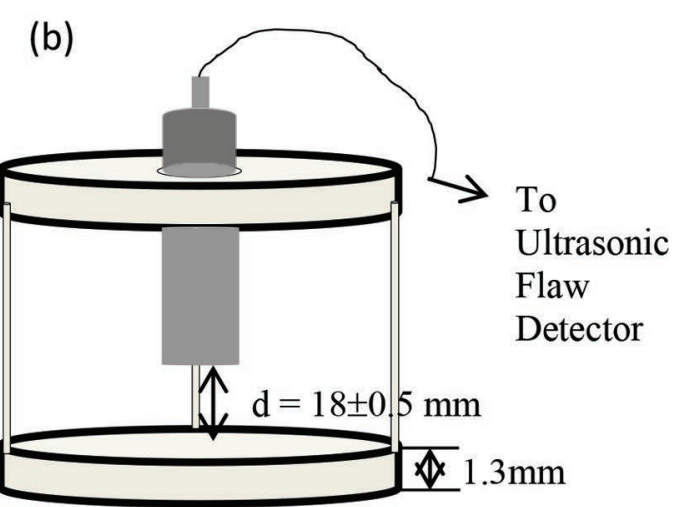

Figure 1. (a) Experimental setup used for characterizing powder dissolution; (b) immersion transducer holder. FBRM = focused beam reflectance measurement; $d=$ distance. Color version available online. 
parameters were compared with the results obtained from the FBRM and solubility index to evaluate the relationship between the dissolution characteristics of the powder and the derived ultrasound parameters.

\section{Solubility Index}

The solubility index was carried out following the method described by Anema et al. (2006). A 15-mL sample was taken at $30 \mathrm{~min}$ and centrifuged at $700 \times g$ for 10 min at $25^{\circ} \mathrm{C}$ using a centrifuge (Fisher Scientific). The TS in the supernatant were determined using the standard method (Anema et al., 2006). The soluble material, $\sigma$, was calculated using Equation 3:

$$
\tilde{\mathrm{A}}=\frac{\text { weight of dry material }}{\text { weight of solution }} \times 100 \% \text {. }
$$

\section{Evaluation of UFD-Based Method}

To evaluate the method, 2 batches of MPC80 from a commercial manufacturer were procured and stored at 25 and $40^{\circ} \mathrm{C}$ for $4 \mathrm{wk}$. The composition of MPC 80 was approximately $80.4 \%$ protein, $5.5 \%$ moisture, $6.6 \%$ ash, $1.1 \%$ fat, and $6.4 \%$ lactose. The dissolution characteristics of the samples were evaluated on $\mathrm{d} 0$ and 3 , as well as wk 1, 2, 3, and 4 . Day 0 powder was referred to as fresh powder. On each experimental day, dissolution properties of MPC were characterized using the UFD, FBRM, and solubility index. In a 1-L beaker, $26.32 \mathrm{~g}$ of MPC80 was gradually added to $500 \mathrm{~g}$ of distilled water. After adding all the powder, data from the UFD and FBRM was acquired every 15 and $10 \mathrm{~s}$, respectively, for 1,800 s. Every 300 s, a 15-mL sample was collected for the solubility index. All tests were done in duplicate.

\section{Statistical Analysis}

Changes in the powder dissolution characteristics observed by the proposed UFD-based method were analyzed by a repeated measures design using the PROC GLM procedure of SAS (Version 9.4, SAS Institute Inc., Cary, NC).

\section{RESULTS AND DISCUSSION}

\section{Optimization of Method Parameters}

From the parameter optimization studies, a 5\% (wt/ wt) concentration was found to be the optimal concentration. To optimize the powder concentration, ultrasound velocity and attenuation curves were obtained with MPC concentrations of 2.5, 5, 7.5, and 10\% (wt/

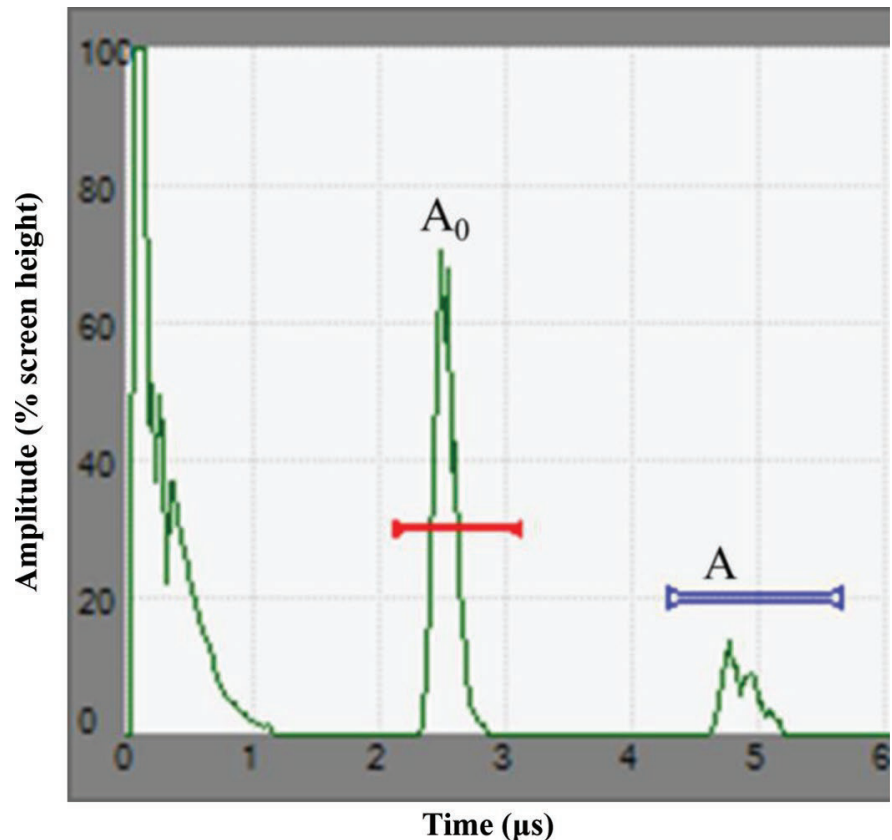

Figure 2. Typical ultrasonic flaw detector signal with the first $\left(A_{0}\right)$ and second peak (A). Color version available online.

wt). An increasing observable trend in ultrasound attenuation and velocity plots was observed during dissolution of MPC for concentrations of 5, 7.5, and $10 \%$. These were found to be acceptable for further studies (data not shown); however, the $2.5 \%$ concentration did not provide an acceptable trend for ultrasound velocity and attenuation and was not considered for subsequent experiments. Keeping in view the time required for addition of MPC to water, it was decided that a $5 \%$ solution was optimum to acquire ultrasound data using an UFD for characterizing powder dissolution.

For the stirring conditions, the overhead stirrer speed was set at $900 \mathrm{rpm}$ during powder addition to reduce the time required to wet all the powder particles. Subsequently, the stirrer speed was reduced to $400 \mathrm{rpm}$ for the remainder of the experiment. Yu and Erickson (2008) reported that a stirrer speed below $400 \mathrm{rpm}$ was not sufficient to keep the powder particles in suspension. Conversely, speed above $400 \mathrm{rpm}$ led to formation of air bubbles and, consequently, a poor ultrasound signal.

During optimization of ultrasound path length (distance between the reflector plate and the transducer), it was observed that the time required for the second echo to reappear was shorter for shorter ultrasound path lengths. It was found from the preliminary experiments that the optimal path length was $18 \pm 0.5 \mathrm{~mm}$. As suggested by the UFD manufacturer and data from preliminary experiments, a damp of $50 \Omega$ and energy 
Table 1. Parameters used in the proposed ultrasonic flaw detector -based method

\begin{tabular}{ll}
\hline Parameter & Selected level \\
\hline Powder concentration $(\% ; w t / w t)$ & 5 \\
Temperature $\left({ }^{\circ} \mathrm{C}\right)$ & $40 \pm 0.1$ \\
Ultrasound path length $(\mathrm{mm})$ & $18 \pm 0.5$ \\
Damp (ohms) & 50 \\
Energy (V) & 100 \\
Stirring speed (rpm) & 900 \\
During powder addition & 400 \\
During data collection & Every $10 \mathrm{~s}$ for $1,800 \mathrm{~s}$ after powder addition \\
Data collection protocol & \\
\hline
\end{tabular}

level of $100 \mathrm{~V}$ were selected. The final method parameters that were used in the evaluation of the proposed method are provided in Table 1.

\section{Evaluation of the UFD-Based Method}

To evaluate the method and dissolution behavior, MPC80 powders stored at 25 and $40^{\circ} \mathrm{C}$ for up to $4 \mathrm{wk}$ were used. According to Anema et al. (2006), MPC85 stored at $20^{\circ} \mathrm{C}$ showed only a little change in solubility over a storage time of $60 \mathrm{~d}$. However, the solubility of MPC85 decreased exponentially with storage temperature and time. Similarly, in the present study we expected a reduction in the solubility of MPC80 and to be able to capture the change in solubility characteristics using the proposed UFD-based method.

Relative Ultrasound Velocity. When MPC 80 was added to water the ultrasound signal disappeared and, consequently, the relative velocity began to fluctuate. Over time, the ultrasound signal gradually reappeared. The time for the signal to reappear increased as the storage time of powder increased, indicating a loss of solubility. The relative ultrasound velocity at $1,800 \mathrm{~s}$ was found to be 0.99 for fresh powder and 0.98 for powder stored at $25^{\circ} \mathrm{C}$ for $4 \mathrm{wk}$. Figure $3 \mathrm{~A}$ shows a typical relative velocity profile obtained for fresh powder. As we can observe from Figure 3A, the relative velocity obtained for the fresh powder samples fluctuated approximately for the first $350 \mathrm{~s}$. On the other hand, the relative velocity obtained for the powders stored at $25^{\circ} \mathrm{C}$ for $4 \mathrm{wk}$ fluctuated for $700 \mathrm{~s}$ and subsequently attained a stable value (Figure 3B). After 3 wk of storage at $40^{\circ} \mathrm{C}$, the relative ultrasound velocity of MPC fluctuated during the entire experimental period of $1,800 \mathrm{~s}$ (Figure 3C). Richard et al. (2012) noticed a similar reduction in the ultrasound signal and attributed the reduction in ultrasound signal to water entering into the powder particles and consequently releasing the air from the powder particles into the solution. Yucel and Coupland (2011) found a similar change in ultrasound velocity immediately after the addition of lactose to water and attributed this to the air bubble formation in the system. Interestingly, in the proposed method, the fluctuation in relative ultrasound velocity was found to strongly depend on the storage time and temperature of the powder and can be used as a parameter to characterize powder dissolution behavior.

To quantify the changes in the powder dissolution characteristics from the relative ultrasound velocity, the standard deviation of relative ultrasound velocity between 900 and 1,800 s was derived as a parameter. Between 900 and 1,800 s, fresh powders showed a relatively stable velocity profile. Powders with a longer storage time were still increasing or fluctuating, which led to an increased standard deviation. Figure 4 shows the calculated relative velocity standard deviation for the powders stored at 25 and $40^{\circ} \mathrm{C}$. The relative velocity standard deviations for powders on $\mathrm{d} 0, \mathrm{~d} 3$, and wk 2 were not significantly $(P>0.05)$ different for powders stored at 25 and $40^{\circ} \mathrm{C}$; this indicates that the powder dissolution characteristics cannot be differentiated using the relative velocity alone as an indicator. However, relative velocity standard deviation was significantly different $(P<0.05)$ for the powders stored at 25 and $40^{\circ} \mathrm{C}$ on experimental wk 1,3 , and 4 . Meyer et al. (2006) observed that the ultrasound velocity measurements were not sufficient to characterize the reconstitution quality of dairy powders.

Ultrasound Attenuation. Figure 5A shows the changes in ultrasound attenuation during dissolution of powders stored for $0 \mathrm{~d}$ as well as 1 and $4 \mathrm{wk}$ at $25^{\circ} \mathrm{C}$. To simplify the plot, d 3 , wk 2 , and wk 3 data were omitted from Figure 5A. During dissolution, the ultrasound attenuation for a fresh powder increased during the first $510 \mathrm{~s}$ and remained relatively stable for the remainder of the experiment. As the storage time increased, the ultrasound attenuation increased at a slower rate. Stabilizing time for wk 1 and 4 samples stored at $25^{\circ} \mathrm{C}$ was found to be around 750 and $950 \mathrm{~s}$, respectively. At the end of the 30-min dissolution time, the ultrasound attenuation was found to be approximately 0.07 neper $(\mathrm{Np}) / \mathrm{mm}$ for the MPC samples stored at $25^{\circ} \mathrm{C}$. Figure $5 \mathrm{~B}$ shows the changes in ultrasound attenuation during dissolution of powders stored for $0 \mathrm{~d}$ as well as 1 and 4 

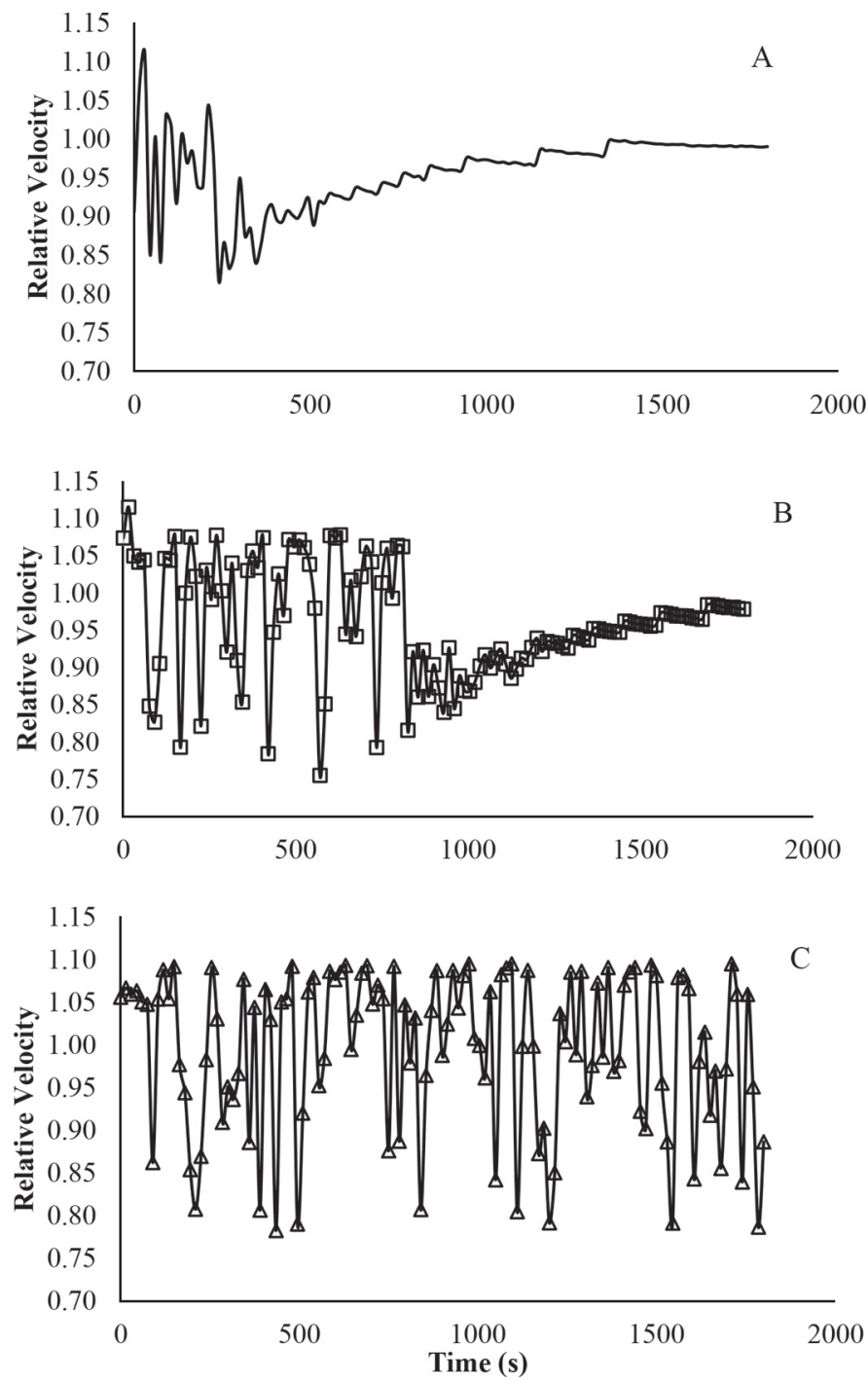

Figure 3. Profiles of relative ultrasound velocity obtained from the ultrasonic flaw detector for fresh powder (A), powders that have been stored at $25^{\circ} \mathrm{C}$ for $4 \mathrm{wk}(\mathrm{B})$, and powders that have been stored at $40^{\circ} \mathrm{C}$ for $4 \mathrm{wk}(\mathrm{C})$.

wk at $40^{\circ} \mathrm{C}$. Also, at $40^{\circ} \mathrm{C}$ an increase in the ultrasound attenuation was delayed as the powder storage time increased. It is evident from Figures $5 \mathrm{~A}$ and $5 \mathrm{~B}$ that the proposed method was able to differentiate the changes in dissolution characteristics for powders stored at 25 and $40^{\circ} \mathrm{C}$, respectively.

To quantify the changes in the attenuation curve, area under the attenuation curve, peak height, and peak time were derived from the attenuation data (Figures $5 \mathrm{~A}$ and $5 \mathrm{~B}$ ). Figure $6 \mathrm{~A}$ shows the changes in the area under the curve over the 4 -wk storage period for the powders stored at 25 and $40^{\circ} \mathrm{C}$. As the storage time and temperature increased, the area under the curve decreased, indicating loss of solubility. No significant $\triangle 40 \square-25$

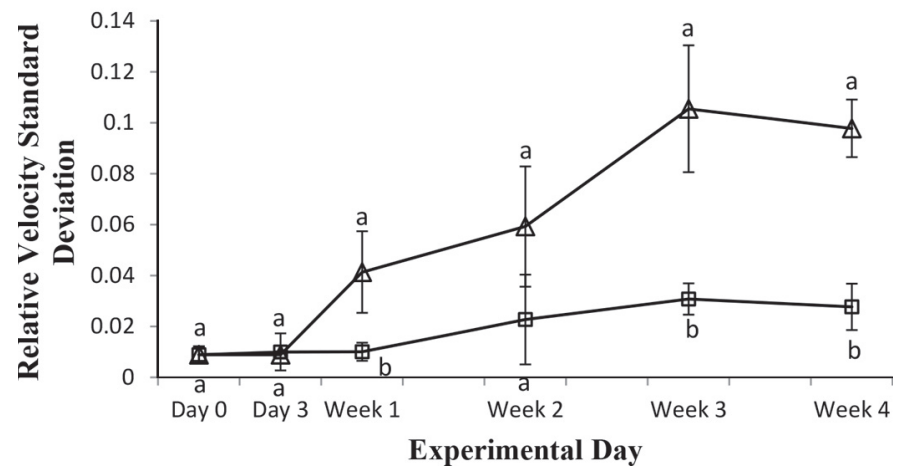

Figure 4. Relative ultrasound velocity standard deviation from 900 to $1,800 \mathrm{~s}$ obtained with the ultrasonic flaw detector on each experimental day for powders stored at 40 and $25^{\circ} \mathrm{C}$. The error bars represent the standard error. Different lowercase letters $(a, b)$ differ between storage temperatures $(P<0.05)$.

differences $(P>0.05)$ were observed on d 0 and 3 between the powders stored at 25 and $40^{\circ} \mathrm{C}$ as observed by the proposed method. However, the powders stored
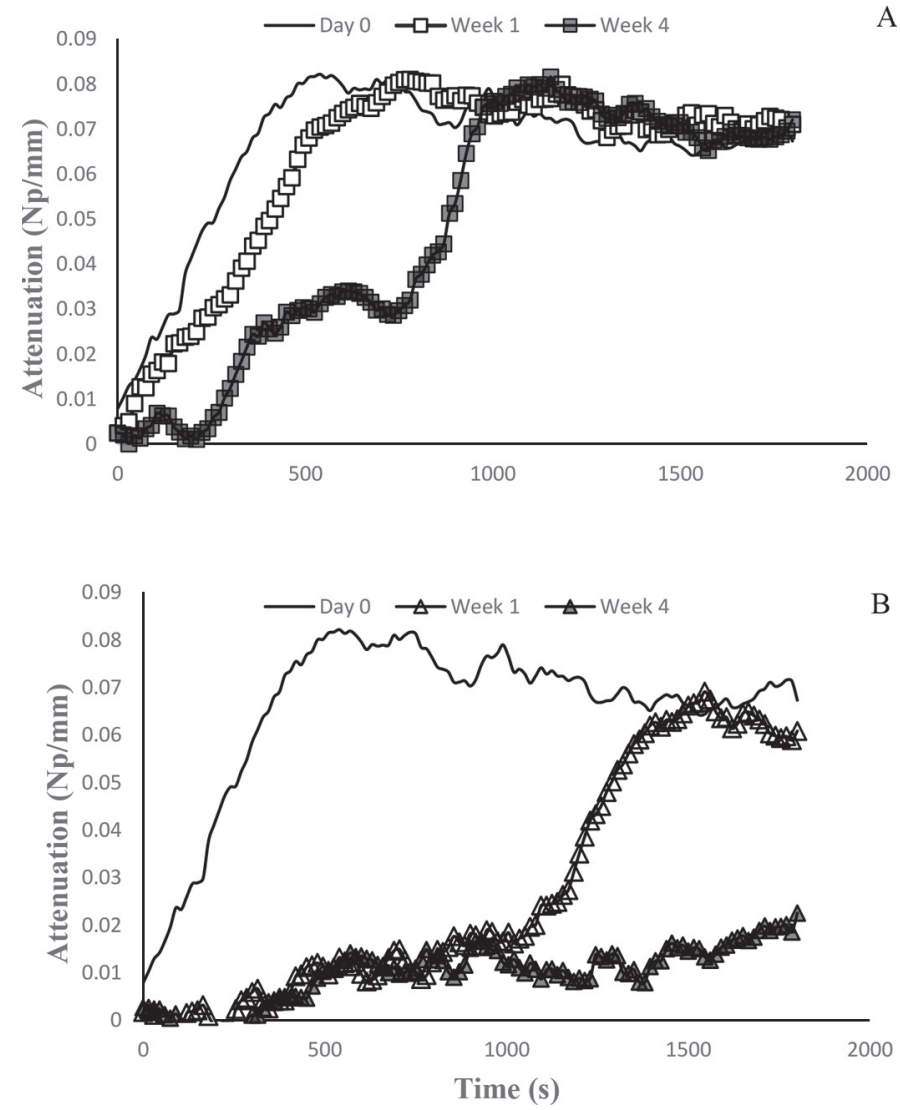

Figure 5. Ultrasound attenuation curves obtained from the ultrasonic flaw detector on d 0 , wk 1 , and wk 4 for powders stored at $25^{\circ} \mathrm{C}$ (A) and $40^{\circ} \mathrm{C}(\mathrm{B}) . \mathrm{Np}=$ neper. 
for more than a week were significantly different $(P<$ 0.05 ) at 25 and $40^{\circ} \mathrm{C}$. Anema et al. (2006) reported a half-life of $5.7 \mathrm{~d}$ for MPC85 stored at $40^{\circ} \mathrm{C}$. For fresh powders, the area was around $100 \mathrm{~Np} \times \mathrm{s} / \mathrm{mm}$. After 4 wk of storage at $25^{\circ} \mathrm{C}$, the area was reduced by $24 \%$ and powders stored at $40^{\circ} \mathrm{C}$ experienced a $78.5 \%$ reduction in area under the attenuation curve.

Figures $6 \mathrm{~B}$ and $6 \mathrm{C}$ show the changes in the attenuation peak height and peak time for the powders stored at 25 and $40^{\circ} \mathrm{C}$, respectively, during storage. It was observed that the peak height decreased and peak time increased as the storage time and temperature increased. With the peak height, powders stored at 25 and $40^{\circ} \mathrm{C}$ were significantly different $(P<0.05)$ on wk 2,3 , and 4 . When observing the peak time, a significant difference $(P<0.05)$ was only noticed for wk 1 and 2 . From Figures $6 \mathrm{~A}, 6 \mathrm{~B}$, and $6 \mathrm{C}$, it can be observed that the area under the attenuation curve followed by peak height parameters were the most informative features to characterize the powder dissolution behavior. Fresh powders had a peak height of $0.0841 \mathrm{~Np} / \mathrm{mm}$ with a peak time of $620 \mathrm{~s}$, whereas powders stored for 4 wk at $25^{\circ} \mathrm{C}$ had a peak of height and peak time of $0.075 \mathrm{~Np} /$ $\mathrm{mm}$ and $1,205 \mathrm{~s}$, respectively. When the powders were stored at $40^{\circ} \mathrm{C}$ for $4 \mathrm{wk}$, the peak height was below 0.03 $\mathrm{Np} / \mathrm{mm}$ and the peak time was around 1,250 s.

\section{FBRM}

The FBRM tracked the number of fine $(<10 \mu \mathrm{m})$, medium $(10-50 \mu \mathrm{m})$, and large $(50-150 \mu \mathrm{m})$ particles as a function of time during dissolution of MPC. Figure $7 \mathrm{~A}$ shows the changes in fine particle counts obtained during dissolution of fresh MPC, MPC stored at $25^{\circ} \mathrm{C}$ for $4 \mathrm{wk}$, and MPC stored at $40^{\circ} \mathrm{C}$ for $4 \mathrm{wk}$. It is evident from Figure 7A that the rate of increase in fine counts reduced as the storage temperature increased. In a study using the FBRM, Fang et al. (2011) noticed that the dissolution rate decreased as the storage temperature and time increased for MPC powders. Fang et al. (2010) also described the initial dissolution rate as the slope of the chord length plot over time, and indicated that the greater magnitude of slope implies a faster dissolution rate of powder. In the current study, fresh powders reached an equilibrium state at a faster rate than the stored powders. Similarly, medium particle counts also increased during the dissolution of MPC (Figure 7B). On the other hand, the large particle counts decreased and reached a minimum depending on the MPC quality (Figure 7C). The large aggregates of MPC powder disintegrated into medium and fine particles and consequently caused an increase in the counts for fine and medium particles. Over the course of the dissolution, the fine and medium particles reached a maximum that
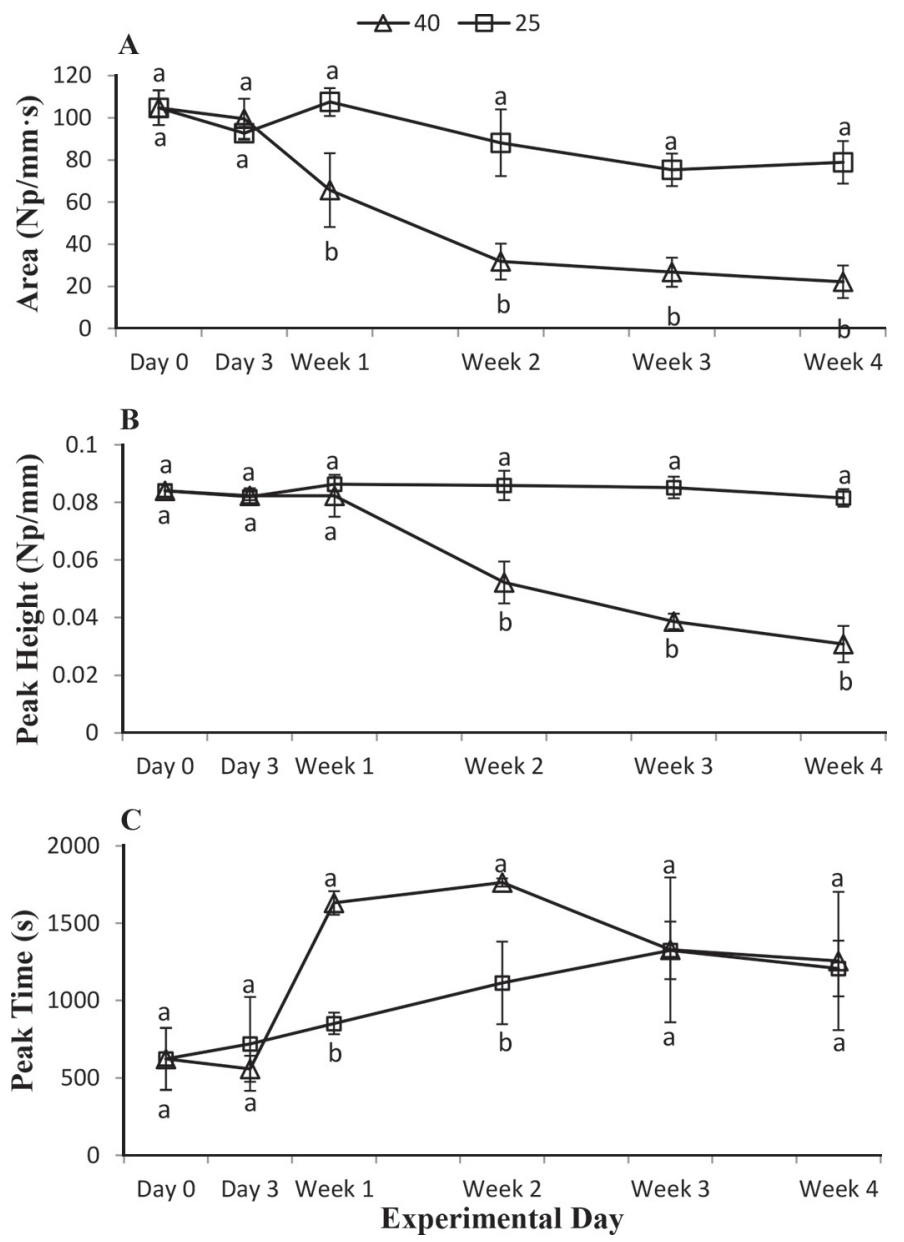

Figure 6. Area under the attenuation curve (A), peak height (B), and peak time $(\mathrm{C})$ extracted from attenuation data collected with the ultrasonic flaw detector on each experimental day for the powders stored at 25 and $40^{\circ} \mathrm{C}$. The error bars represent the standard error. Different lowercase letters $(\mathrm{a}, \mathrm{b})$ differ between storage temperatures $(P<0.05) . \mathrm{Np}=$ neper.

was maintained for the remainder of the experiment. Overall, the FBRM captured the changes between fresh powders and powders that had been stored for $4 \mathrm{wk}$ at 25 and $40^{\circ} \mathrm{C}$.

\section{Solubility}

Over the 4-wk storage period, the powders stored at $25^{\circ} \mathrm{C}$ did not experience a major change in solubility as measured using the solubility index. Anema et al. (2006) also reported that the MPC85 stored at $20^{\circ} \mathrm{C}$ showed only a little change in solubility over $60 \mathrm{~d}$ of storage. However, the solubility was reduced to $47.7 \%$ for the powders stored at $40^{\circ} \mathrm{C}$ for 4 wk. Anema et al. (2006) reported that the solubility of MPC85 stored at $40^{\circ} \mathrm{C}$ was acceptable only for the first $2 \mathrm{~d}$ and decreased rapidly over the next $10 \mathrm{~d}$. In the present study, 

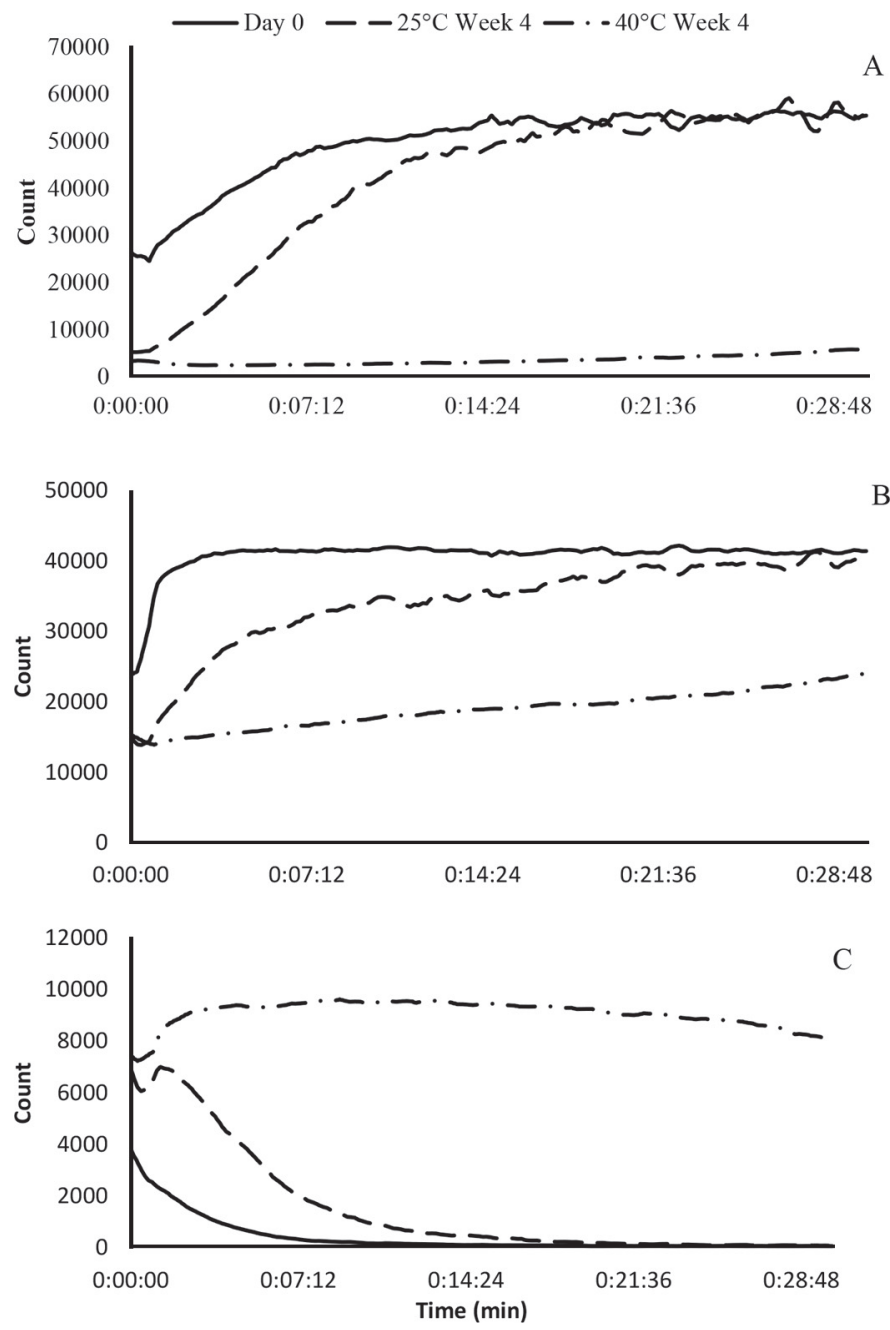

Figure 7. Change in fine (A), medium (B), and large $(\mathrm{C})$ counts obtained from the focused beam reflectance measurement for $\mathrm{d} 0$, and powders that have been stored at 25 and $40^{\circ} \mathrm{C}$ for 4 wk during an experiment.

MPC 80 solubility at $40^{\circ} \mathrm{C}$ was approximately $97 \%$ on wk 1 and reduced rapidly thereafter. Figure 8 presents the solubility on each experimental day for the MPC powders stored at 25 and $40^{\circ} \mathrm{C}$. A significant difference $(P<0.05)$ was not observed between storage at 25 and $40^{\circ} \mathrm{C}$ until wk 2 . This indicates that the solubility index as a method was less sensitive in capturing the changes in powder dissolution characteristics.

\section{Comparing Ultrasound, FBRM, and Solubility Data}

For powders to dissolve quickly, water must be able to penetrate the particles (Richard et al., 2012). However, MPC powders that have been exposed to high temperatures for long periods of time produce a shell structure that inhibits water from penetrating the par- ticle and reduce the dissolution rate (Fang et al., 2011).

The reduction in dissolution rate caused by storage temperature and time was captured by the UFD-based method, as well as solubility index methods. However, the proposed UFD-based method was able to differentiate the powders stored at 25 and $40^{\circ} \mathrm{C}$ for 1 wk. This indicates that the proposed UFD-based method is more sensitive than the solubility method in detecting changes in powder dissolution. As the dissolution rate decreases, the powders take longer to reach an asymptotic value for the ultrasonic amplitude (Richard et al., 2012). With the powders in our study, the peak time increased as the solubility of the powders decreased. The FBRM and solubility index showed that storing the MPC for 4 wk at 25 and $40^{\circ} \mathrm{C}$ decreased the dissolution rate and solubility of the powder. The ultrasound data also showed that, as the dissolution rate and solubility decreased, the area under the attenuation curve and attenuation peak height decreased and the attenuation peak time and relative velocity standard deviation increased. Thus, a soluble powder will have a low relative standard deviation, low attenuation peak time, high area under the attenuation curve, and high attenuation peak height.

\section{CONCLUSIONS}

A new and rapid method using an UFD was developed to characterize the dissolution of high-protein dairy powders, specifically MPC, for this study. The FBRM and solubility index were used as reference methods. From the velocity and attenuation graphs, the velocity standard deviation from 900 to $1,800 \mathrm{~s}$, area under the attenuation curve, attenuation peak height, and attenuation peak time were derived to characterize

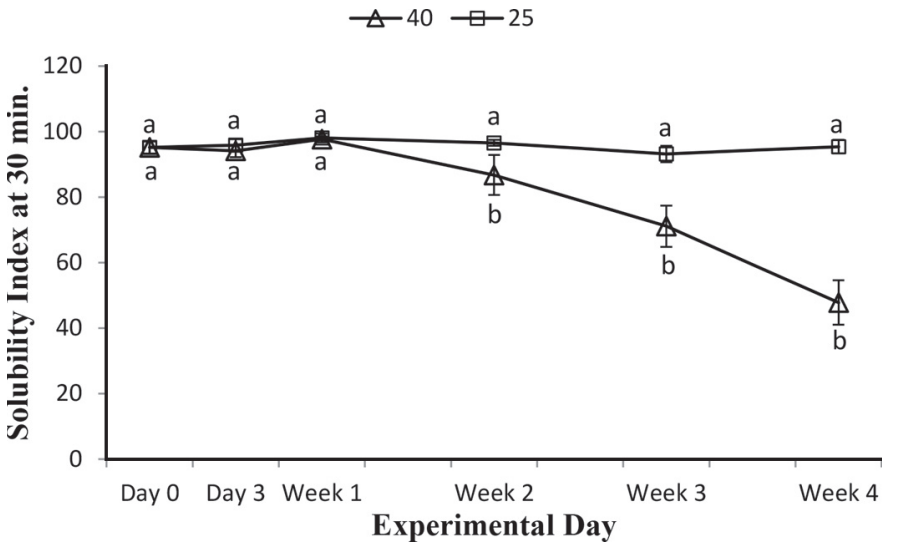

Figure 8. Solubility index at $30 \mathrm{~min}$ on each experimental day for powders stored at 25 and $40^{\circ} \mathrm{C}$. The error bars represent the standard error. Different lowercase letters $(\mathrm{a}, \mathrm{b})$ differ between storage temperatures $(P<0.05)$. 
the dissolution of the MPC. The FBRM and solubility index showed that the dissolution rate decreased as the storage time and temperature increased. The derived parameters from the relative velocity and attenuation curves clearly show potential to characterize the powder dissolution. A decrease in solubility caused an increase in the standard deviation of relative velocity and attenuation peak time, and a decrease in the peak height and area under the curve. When used as a routine method to assess the solubility of a powder, the best ultrasound parameters to consider for evaluating powder solubility are the relative velocity standard deviation from 900 to $1,800 \mathrm{~s}$ and area under the attenuation curve. Overall, a UFD can be used on a routine basis as a lowcost method to characterize the dissolution behavior of high-protein dairy powders.

\section{ACKNOWLEDGMENTS}

We thank Midwest Dairy Foods Research Center (St. Paul, MN) for their financial support. This article is Kansas State Research and Extension contribution number 15-430-J.

\section{REFERENCES}

Agarwal, S., R. L. W. Beausire, S. Patel, and H. Patel. 2015. Innovative uses of milk protein concentrates in product development. J. Food Sci. 80:A23-A29.

Anema, S. G., D. N. Pinder, R. J. Hunter, and Y. Hemar. 2006. Effects of storage temperature on the solubility of milk protein concentrate (MPC85). Food Hydrocoll. 20:386-393.

Chandan, R. C., and A. Kilara. 2011. Dairy Ingredients for Food Processing. Wiley-Blackwell, Ames, IA.

Corredig, M. 2009. Dairy-Derived Ingredients Food and Nutraceutical Uses. CRC Press, Boca Raton, FL.

Corredig, M., M. Alexander, and D. G. Dalgleish. 2004. The application of ultrasonic spectroscopy to the study of the gelation of milk components. Food Res. Int. 37:557-565.

Dolatowski, Z. J., J. Stadnik, and D. Stasiak. 2007. Applications of ultrasound in food technology. Acta Sci. Pol. Technol. Aliment. 6:89-99.
Fang, Y., C. Selomulya, and X. Chen. 2008. On measurement of food powder reconstitution properties. Dry. Technol. 26:3-14.

Fang, Y., C. Selomulya, and X. Chen. 2010. Characterization of milk protein concentrate solubility using focused beam reflectance measurement. Dairy Sci. Technol. 90:253-270.

Fang, Y., C. Selomulya, S. Ainsworth, M. Palmer, and X. D. Chen. 2011. On quantifying the dissolution behaviour of milk protein concentrate. Food Hydrocoll. 25:503-510.

Gunasekaran, S., and C. Ay. 1996. Milk coagulation cut-time determination using ultrasonics. J. Food Process Eng. 19:63-73.

Kneifel, W., P. Paquin, T. Abert, and J. P. Richard. 1991. Waterholding capacity of proteins with special regard to milk proteins and methodological aspects-A review. J. Dairy Sci. 74:2027-2041.

Leemans, V., and M. Destain. 2009. Ultrasonic internal defect detection in cheese. J. Food Eng. 90:333-340.

McClements, D. J. 1995. Ultrasonic characterization of foods. Pages 93-116 in Characterization of Food. A. G. Gaonkar, ed. Elsevier Science B.V., Amsterdam, the Netherlands.

Meyer, S., V. S. Rajendram, and M. J. W. Povey. 2006. Characterization of reconstituted milk powder by ultrasound spectroscopy. J. Food Qual. 29:405-418.

Nassar, G., F. Lefbvre, A. Skaf, J. Carlier, B. Nongaillard, and Y Noêl. 2010. Ultrasonic and acoustic investigation of cheese matrix at the beginning and the end of ripening period. J. Food Eng. 96:1-13.

Olympus. 2007. EPOCH LTC Ultrasonic Flaw Detector User's Manual. Version C ed. Olympus, Tokyo, Japan.

Pico, Y. 2012. Low-intensity ultrasounds. Pages 117-144 in Chemical Analysis of Food: Techniques and Applications. Y. Picó ed. Academic Press, Boston, MA.

Povey, M. J. W., and D. J. McClements. 1988. Ultrasonics in food engineering. Part I: Introduction and experimental methods. J. Food Eng. 8:217-245.

Quinn, J., and D. Paton. 1979. A practical measurement of water hydration capacity of protein materials. Cereal Chem. 56:38-40.

Richard, B., M. Toubal, J. Le Page, G. Nassar, E. Radziszewski, B. Nongaillard, P. Debreyne, P. Schuck, R. Jeantet, and G. Delaplace. 2012. Ultrasound tests in a stirred vessel to evaluate the reconstitution ability of dairy powders. Innov. Food Sci. Emerg. Technol. $16: 233-242$.

Wallingford, L., and T. P. Labuza. 1983. Evaluation of the water binding properties of food hydrocolloids by physical/chemical methods and in a low fat meat emulsion. J. Food Sci. 48:1-5.

Yu, W., and K. Erickson. 2008. Chord length characterization using focused beam reflectance measurement probe-Methodologies and pitfalls. Powder Technol. 185:24-30.

Yucel, U., and J. N. Coupland. 2011. Ultrasonic characterization of lactose crystallization in gelatin gels. J. Food Sci. 76:E48-E54. 